\title{
STEROLS COMPOSITION OF SOME OLIVE OIL VARIETIES CULTIVATED UNDER EGYPTIAN CONDITIONS
}

\author{
EID, M. M. AND M. E. I. ELSORADY \\ Oils and Fats Dept, Food Tech. Res. Inst., ARC, Giza, Egypt. \\ (Manuscript received 2 October 2011)
}

\begin{abstract}
The sterol composition of some Egyptian olive oils (Coratina, Arbequina, Koroneiki and Siwi were analyzed during season (20102011), to obtain a more complete characterization of these varietal oils. More than nine compounds were identified and characterized. As expected for virgin olive oil (VOOs), the main sterols found in all VOOs were $\beta$-sitosterol, $\Delta 5$-avenasterol, campesterol and stigmasterol. Cholesterol, clerosterol, sitostanol, $\Delta 5,24-$ stigmastadienol, and $\Delta 7$-avenasterol were also found in lower amounts for all VOOs. The majority of the Egyptian virgin olive oils analyzed comply with the using EC Regulation No. 2568, except for Arbequina VOO. Total sterol amounts were higher than the minimum limit set by legislation, ranging from 1562.32 to 2550.62 $\mathrm{mg} / \mathrm{kg}$. Coratina VOO showed the highest contents of $\beta$-sitosterol $(84.24 \%)$ while, Siwi VOO showed the highest $\Delta 5$ avenasterol $(8.66 \%)$. Arbequina VOO had the lowest content of $\beta$-sitosterol (50.63\%) and $\Delta 5$ avenasterol (4.75\%).

Quality characteristics (acidity, peroxide value, $K_{232}, K_{270}$, $\Delta \mathrm{K}_{1}$ ), chemical data (Total phenols, oxidative stability, fatty-acid composition, and sterol composition) were also studied. The obtained results were compared with International Olive Oil Standards. The total phenol content ranged from 105.07 to 195.17 $\mathrm{mg} / \mathrm{kg}$, showing the highest values for Coratina and Koroneiki VOOs. Arbequina VOO presented the highest deviations from the IOC in fatty acids and sterol percentages, so that Arbequina virgin olive oil stood out of IOC and EU limits.
\end{abstract}

Keywords: Sterols composition, olive oils, Coratina, Arbequina, Koroneiki, Siwi cultivars.

\section{INTRODUCTION}

Olive oil is obtained from the fruit of olive trees (Olea europaea L.) and is a genuine fruit juice with excellent nutritional, sensorial and functional quality. It represents a typical lipid source of the Mediterranean diet, which consumption has been associated with a low incidence of cardiovascular diseases, neurological disorders, breast and colon cancers, as well as with hipolipidemic and antioxidant properties (Matos et. al., 2007). Olive oil is one of the oldest known vegetable oils mainly produced in the countries surrounding the Mediterranean Sea. It is a natural fruit juice, obtained from the fruit of tree Olea europaea L., with a unique composition and quality. Olive oil is one of the very few oils that can be consumed in its natural 
form, thus preserving all its natural constituents. Several methods of analysis have been proposed and are affected by several factors, including packaging (Kiritsakis, 1998).

The consumption of extra virgin olive oil, the most characteristic component of the Mediterranean diet, is currently increasing because of its nutritional and healthpromoting effects, which have been related to the optimal balance between saturated, monounsaturated (MUFA), and polyunsaturated fatty acids (PUFA), as well as to minor components such as sterols, chlorophyll, polyphenols and tocopherols. The chemical composition and quality of virgin olive oil are influenced by a variety of factors, among them geographical production area (altitude and soil composition), climatic conditions prevailing in the production year, cultivar, and extraction process (Kiritsakis, 1998, Dag et. al., 2011).

The chemical compounds of olive oil can be divided into two groups: the saponifiable fraction, which accounts for almost the entire weight of the oil (98-99\% of total weight) and the nonsaponifiable fraction, which represents $0.5-2.0 \%$ of the total weight and is constituted of diverse components that are of great importance in terms of its biological value, together with some constituents characterized by their antioxidant activities, which can be measured using methods based on diverse radical generating systems (Samaniego -Sanchez et. al., 2010) .

The nutritional quality of virgin olive oil has been related to its composition, in particular the high concentration of oleic acid, which accounts for about $55-83 \%$ of the total fatty acids (Codex Alimentarius and IOC). This monounsaturated fatty acid favours the reduction of LDL cholesterol and is related to the prevention of cardiovascular diseases. However, VOO nutritional quality has also been associated with its minor components, mainly antioxidants such as tocopherols (chiefly atocopherol) and polar phenols, but also sterols (mainly $\beta$-sitosterol), and pigments (chlorophylls, carotenoids), which also play a role in the stability of the oil and the prevention of cardiovascular diseases, tumors and degenerative diseases of aging (Inarejos-García et. al., 2010). Minor compounds are of great importance in the final composition of olive oil because they influence the stability and overall acceptability as well as the nutritional and health related properties of the olive oil. Compounds such as sterols, squalene, and tocopherols are of great interest as high value added products because of their nutraceutical activities (Ibaneza et. al., 2002).

Sterols are nutritionally important lipids that need to be routinely determined in foods. In olive oil, content and composition of sterols can vary due to the agronomic and climatic conditions, fruit or seed quality, oil extraction and refining procedures and storage conditions Plant sterols or phytosterols make up the main part 
of the unsaponifiable fraction of olive oil. Their composition depends on the kind of olive oil. Chemical structures of these sterols are similar to cholesterol (EEC, 2003). The most abundant olive oil sterol is $\beta$-sitosterol, followed by $\Delta 5$-avenasterol. Campesterol and stigmasterol are present in lower concentrations ( IOC, 2006). Compositional analysis of the sterol fraction of olive oil can be used to assess the degree of purity of the oil and the absence of other plant oils. This determination also permits characterization of the type of olive oil in question: extra virgin, virgin, refined, etc... (EEC, 2003).

The composition of the steroidal fraction of the olive oil is a very useful parameter for detecting adulterations or to check authenticity, since it can be considered as its real fingerprint (Pardo et. al., 2011). Recently, it has also been proposed that sterol profiles could be used to classify virgin olive oils according to their fruit variety (Rivera del Alamo et. al., 2004).

Sterols are important components in human health and nutrition. Phytosterols found in vegetables and plant oils, such as $\beta$-sitosterol have been shown to reduce cholesterol absorption in humans resulting in reduced health problems ( Mailer et. al., 2010). Additionally, it has been suggested that phytosterols have anti-inflammatory antibacterial, antifungal, antiulcerative and antitumoral activities. Sterols have also been recognized as cancer-preventive biologically-active substances, together with other secondary plant products. Also, they apparently help to reduce total plasma cholesterol and LDL cholesterol, and as a result these compounds are being considered as ingredients of functional foods (Ben Temime et. al., 2008).

The International Olive Council (IOC) imposes limits or ranges for each type of sterol based on the natural levels found in traditional olive oil types. Sterol profiles outside these ranges could suggest that the olive oil is not genuine. A number of cases have found olive oils which naturally exceed the limits for sterols. This is particularly so in the case of campesterol which is specified to be less than $4 \%$ of total sterols according to the standard limits. Cultivars in which the campesterol content has exceeded this limit include Arbequina, Corniche, Koroneiki, Cornicabra, Arauco and Barnea . Erythrodiol levels are high in solvent extracted or refined oils (i.e. pomace oils) and therefore high levels in virgin oils would indicate adulteration with pomace oil (Rivera del Alamo et. al., 2004, Mailer et. al., 2010).

Several factors are known to affect the quantitative sterolic profiles of olive fruits. Among these factors, the ripening cycle of the fruit and the nature of the cultivar, oil extraction and refining procedures and storage conditions. The effects of agronomic and climatic conditions have also been studied. However, the total effect of these variables on sterol profiles is ambiguous. The diversity of these factors and their 
interrelationships make it very difficult to completely characterize the sterol profile and erythrodiol + uvaol content of a given product (Ben Temime et. al., 2008).

The objective of this investigation is to define sterol composition of some Egyptian olive oils (Coratina, Arbequina, Koroniki and Siwi cultivars).

\section{MATERIALS AND METHODS}

\subsection{Virgin olive oil samples:}

Olive's fruits (Coratina, Arbequina, Koroneiki and Siwi cultivars) were harvested from Agricultural Research Center, Giza, Egypt during season (2010-2011). On the same day of harvest, olive oil was extracted from the above cultivars using the continuous extraction system two-phases. The oil percent was calculated on fresh weight basis directly after oil extraction. The extracted olive oils were stored in refrigerator until use.

\subsection{Analytical methods:}

\subsection{1: Physicochemical quality parameters:}

Free acidity, peroxide value and UV absorption characteristics were carried out following the analytical methods described in Regulations EEC/1989/2003 of the Commission of the European Union (EEC, 2003). Free acidity was expressed as \% of oleic acid, peroxide values were expressed as ml-equivalents of active oxygen per kilogram of oil (meq O2/ kg), $\mathrm{K}_{232}$ and $\mathrm{K}_{270}$ extinction coefficients were calculated from absorption at 232 and $270 \mathrm{~nm}$, respectively.

\subsection{2.: Oxidative stability (Rancimat):}

The oxidative stability was estimated by measuring the oxidation induction time, on a Rancimat apparatus (Metrohm series 679, Switzerland) (Gutierrez, 1989). Air (20 L/h) was bubbled through the oil $(5 \mathrm{~g})$ heated at $100^{\circ} \mathrm{C}$, with the volatile compounds being collected in water, and the increasing water conductivity continually measured. The time taken to reach the conductivity inflection was recorded.

\subsection{3.: Total phenols:}

Total phenols (TP) content of the methanolic extract of olive oil were calorimetrically determined using the Folin-Ciocalteu method (Gamez-Meza et. al., 1999) where an aliquot $(1 \mathrm{ml})$ of methanolic extract was mixed with diluted ethanol amine $(1 \mathrm{ml})$ at room temperature. After $5 \mathrm{~min}$ the absorbance was measured at 750 nm using a spectrophotometer (JENWAY 6405 UV/Vis .Spectrophotometer, England). 


\subsection{4.: Gas chomatography analysis of fatty acid composition:}

\section{- Methylation of fatty acids}

An aliquot of fatty acids, about $10 \mathrm{mg}$, was dissolved in $2 \mathrm{ml}$ hexane and then $0.4 \mathrm{ml} \mathrm{Zn} \mathrm{KOH}$ in anhydrous methanol was added (Cossignani et. al., 2005), after 3 min, $3 \mathrm{ml}$ water was added. The organic layer, separated by centrifugation, was dried over anhydrous sodium sulfate, and then concentrated, with a N2 stream to around $0.5 \mathrm{ml}$ for GC analysis of fatty acids methyl esters (FAME) as described below.

\section{GC analysis of FAME}

Agilent 6890 series GC apparatus provided with a DB-23 column $(60 \mathrm{~m} \times 0.32$ $\mathrm{mm} \times 0.25 \mu \mathrm{m})$ was used. Fatty acids results after the previous procedures steps were transformed into methyl esters and directly injected into the GC.

\subsection{5.: Sterols composition}

A $5 \mathrm{~g}$ oil sample was dissolved in $3 \mathrm{ml}$ of hexane, and then $0.5 \mathrm{~m} 1$ of $5 \propto-$ cholestane $\left(0.4 \mathrm{mg} \mathrm{ml}^{-1}\right)$ internal standard was added. The mixture was saponified with sodium hydroxide solution in methanol $(2 \mathrm{~N})$ at water bath for 1-2 $\mathrm{h}$. Then, unsaponifaible matters were extracted. Then $1 \mu 1$ of the sample was injected into a Agilent 6890 series GC apparatus (setup:DB-5 capillary column, A $\mathrm{N}_{2}$ carrier gas at $0.9 \mathrm{ml} \mathrm{min}{ }^{-1}$ constant flow rate, split/splitless injector at $230^{\circ} \mathrm{C}$ in the split less mode. Oven temperature: $50^{\circ} \mathrm{C}$ holds for $2 \mathrm{~min}$, ramped to $230^{\circ} \mathrm{C}$ at $15^{\circ} \mathrm{C} \mathrm{min}{ }^{-1}$, ramped to $310^{\circ} \mathrm{C}$ at $3^{\circ} \mathrm{C} \mathrm{min}^{-1}$ hold for $10 \mathrm{~min}$. The internal standard method ( $5 \propto$ - cholestane) was used for quantification (Szterk et. al., 2010).

Analytical determinations were carried out at least in duplicate.

\section{RESULTS AND DISCUSSION}

\subsection{Physicochemical quality parameters:}

Table 1 shows the physicochemical quality parameters for some Egyptian olive oils from different varieties. All the oils analyzed showed very low values for the regulated physicochemical parameters evaluated (acidity $\leq 0.8$, peroxide value $\leq 20$ meq $\mathrm{O}_{2} / \mathrm{kg}, \mathrm{K}_{270} \leq 0.22, \mathrm{~K}_{232} \leq 2.5$ ), with all of them falling within the "extra virgin" category, as stated by Regulation EC/1989/2003 (EEC, 2003), since the raw material was carefully selected, picked and processed. The lower values for these parameters will indicate the higher quality of oil. 
Table 1. Physicochemical quality parameters of some Egyptian olive oils

\begin{tabular}{|c|c|c|c|c|}
\hline Characters & Coratina & Arbequina & Koroneiki & Siwi \\
\hline FFA \%(as Oleic acid) & 0.49 & 0.80 & 0.43 & 0.63 \\
\hline $\begin{array}{c}\text { Peroxide value (meq O 2 kg } \\
\text { oil) }\end{array}$ & 2.23 & 2.51 & 2.73 & 3.85 \\
\hline $\mathrm{K}_{232}$ & 1.697 & 2.157 & 1.891 & 1.786 \\
\hline $\mathrm{K}_{270}$ & 0.111 & 0.128 & 0.161 & 0.091 \\
\hline$\Delta \mathrm{k}$ & -0.003 & -0.009 & 0.010 & -0.014 \\
\hline Oil Content \% & 18.5 & 13.6 & 17.2 & 17.4 \\
\hline (Fresh weight basis) & & & & \\
\hline
\end{tabular}

\subsubsection{Free acidity}

Free fatty acid content, as \% oleic acid, ranged from 0.43 for Koroneiki VOO up to 0.80 for Arbequina VOO\%. None of the oils exceeded the limit of $0.80 \%$ free acidity, the upper threshold limit for the 'extra virgin' category (EEC Regulations) (EEC, 2003). . These results agreed with those reported by Elsorady (2011) studying the same varieties (Coratina, Arbequina and Koroneiki).

\subsubsection{Peroxide value}

Peroxide value, expressed as meq $\mathrm{O}_{2} / \mathrm{kg}$, ranged between 2.23 and 3.85. All of the oils had not a peroxide value higher than the upper limit of 20 established for the 'extra-virgin' olive oil. Also these results agreed with (Elsorady, 2011)

\subsubsection{UV characteristics}

Respect to the UV characteristics, none of the oils had $\mathrm{K}_{232}, \mathrm{~K}_{270}$ and $\Delta \mathrm{K}$ values higher than the limits established for 'extra-virgin' olive oils. $K_{232}$ was between 1.697 (Coratina VOO) and 2.157 (Arbequina VOO). Also, $\mathrm{K}_{270}$ was between 0.091 (Siwi VOO) and 0.161 (Koroneiki VOO) and $\Delta \mathrm{K}$ in the range of -0.014 (Siwi VOO) to 0.010 (Arbequina VOO). The results of Coratina and Koroneiki VOOs agreed with the results obtained by Stefanoudaki et al. (2011).

Table (1) showed that Coratina cultivar had the highest oil content (18.5\%), followed by Siwi and Koroneiki cultivars (17.4, 17.2\%), respectively. On the other hand, Arbequina cultivar had the lowest oil content (13.6\%) 


\subsection{0xidative stability:}

Stability parameters are shown in Table (2). The oxidative stability at $100{ }^{\circ} \mathrm{C}$ and the total phenol content were useful for discriminating among varieties.

Table 2. Stability Parameters of some Egyptian olive oils

\begin{tabular}{|c|c|c|c|c|}
\hline Characters & Coratina & Arbequina & Koroneiki & Siwi \\
\hline Oxidative stability $(\mathrm{h})$ & 32.51 & 12.10 & 31.99 & 18.8 \\
\hline Total phenols $(\mathrm{mg} / \mathrm{kg})$ & 195.17 & 105.07 & 187.25 & 145.53 \\
\hline
\end{tabular}

Oxidative stability of the studied olive oils ranged from $12.10 \mathrm{~h}$ for Arbequina VOO to $32.51 \mathrm{~h}$ for Coratina VOO. These results agreed with (Ceci and Carelli. 2007).

\subsection{Total phenols:}

Virgin olive oil contains phenolic substances which affect its stability and flavor. The highest content of total phenols was $195.17 \mathrm{mg} / \mathrm{kg}$ for Coratina VOO followed by $187.25,145.53$ and $105.07 \mathrm{mg} / \mathrm{kg}$ for Koroneiki, Siwi and Arbequina VOOs, respectively.

The antioxidant activity of hydrophilic phenols of virgin olive oil has been extensively studied. As reported by several investigators, the concentration of phenolic compounds, evaluated colorimetrically and expressed as total phenols, shows a correlation with the shelf-life of virgin olive oil as tested by accelerated methods such as Rancimat (Clodoveo et. al., 2007). Direct correlation was observed between total phenol content and oxidative stability by Rancimat (Table 2 ). Arbequina VOO, which had the lowest total phenol content, showed the lowest oxidative stability. On the other hand, Coratina VOO, which had the highest total phenols, showed the highest oxidative stability.

\section{4.: Fatty acid composition}

Results of fatty acids, total saturated fatty acids (SFA), polyunsaturated fatty acids (PUFA), monounsaturated fatty acids (MUFA), and the ratios $C_{18: 1} / C_{18: 2}$ and MUFA/PUFA for some Egyptian olive oils are shown in Table 3. 
Table 3. Fatty acids composition of some Egyptian olive oils

\begin{tabular}{|c|c|c|c|c|}
\hline Fatty acid & Coratina & Arbequina & Koroneiki & Siwi \\
\hline$C_{16: 0}$ & 15.01 & 22.10 & 15.66 & 13.76 \\
\hline$C_{16: 1}$ & 0.63 & 3.77 & 1.31 & 0.61 \\
\hline$C_{17: 0}$ & 0.04 & 0.18 & 0.05 & 0.05 \\
\hline$C_{17: 1}$ & 0.06 & 0.20 & 0.07 & 0.06 \\
\hline $\mathrm{C}_{18: 0}$ & 2.07 & 1.75 & 2.20 & 2.51 \\
\hline$C_{18: 1}$ & 65.83 & 42.55 & 70.33 & 69.80 \\
\hline$C_{18: 2}$ & 13.72 & 27.62 & 7.98 & 10.83 \\
\hline$C_{18: 3}$ & 0.99 & 1.05 & 0.90 & 0.81 \\
\hline$C_{20: 0}$ & 0.45 & 0.38 & 0.49 & 0.36 \\
\hline$C_{20: 1}$ & 0.46 & 0.21 & 0.34 & 0.29 \\
\hline$C_{22: 0}$ & 0.11 & 0.10 & 0.13 & 0.08 \\
\hline$C_{24: 0}$ & 0.63 & 0.09 & 0.54 & 0.84 \\
\hline$\Sigma$ SFA* & 18.31 & 24.60 & 19.07 & 17.60 \\
\hline$\Sigma$ USFA $^{* *}$ & 81.69 & 75.40 & 80.93 & 82.40 \\
\hline MUSFA & 66.98 & 46.73 & 72.05 & 70.76 \\
\hline PUSFA & 14.71 & 28.67 & 8.88 & 11.64 \\
\hline $\mathrm{C}_{18: 1} / \mathrm{C}_{18: 2}$ & 4.80 & 1.54 & 8.81 & 6.45 \\
\hline MUSFA / PUSFA & 4.55 & 1.63 & 8.11 & 6.08 \\
\hline
\end{tabular}

* SFA : Saturated Fatty Acids.

** USFA : Unsaturated Fatty Acids.

The distribution of fatty acid composition (Table 3) covered the normal range expected for olive oil ( Pardo et. al., 2011) . The highest content of palmitic acid (22.10\%) was found in Arbequina VOO. The palmitoleic acid content was also higher in Arbequina VOO (3.77\%) than in the others. Also, Arbequina VOO showed the highest linoleic values (27.62\%). The oleic and linoleic acid contents were the most useful and significant parameters for differentiating varieties, Koroneiki and Siwi, from the others. Both varieties showed high oleic values.The low oleic and high linoleic acid contents shown by Arbequina VOO seemed to contribute to their low oxidative stability, since this leads to a low mono/polyunsaturated ratio ( Pardo et. al., 2011). Coratina, Koroneiki and Siwi varieties produced oils with excellent fatty acid (FA) composition, i.e., a high level of oleic acid (maximum of $70.33 \%$ ), low palmitic and 
linoleic acid content (minimum of $13.76 \%$ and $7.98 \%$, respectively). These levels were established for extra virgin olive oil (EVOO) (EEC, 2003). Also, Arbequina VOO was out the legal ranges stated by the IOC for fatty acids (IOC, 2006, EEC, 2003). These results were in agreement with Elsorady (2011) for the same cultivars in a different season and also with (Ceci and Carelli, 2007).

The same results revealed that, Arbequina VOO showed the highest mean value for SFA and PUSFA (24.60 and $28.67 \%$, respectively), while Koroneiki VOO showed the highest mean value for MUSFA (72.05\%). Siwi VOO was the highest mean value for USFA ( $82.40 \%)$.

The ratios $\mathrm{C}_{18: 1} / \mathrm{C}_{18: 2}$ and MUSFA / PUSFA were also different among the oils, Arbequina VOO was the lowest value for the ratios $C_{18: 1} / C_{18: 2}$ and MUSFA / PUSFA (1.54 and 1.63, respectively) and Koroneiki was the highest (8.81 and 8.11, respectively). In Siwi and Coratina VOOs, the values were intermediate $(6.45,6.08$ and 4.80, 4.55 for the ratios $C_{18: 1} / C_{18: 2}$ and MUSFA / PUSFA, respectively). The oleic to linoleic acids ratio is frequently used as a stability parameter and, in previous studies, the cultivars with higher ratios were those with higher oxidative stability (Matos et al.,2007). Koroneiki and Siwi VOOs had the highest average values for MUSFA/PUSFA ratio (8.11 and 6.08, respectively) in accordance with their higher oxidative stability indexes. Coratina VOO was within fatty-acid legal ranges. Although Coratina sample showed a medium MUSFA/PUSFA value (4.55), its oxidative stability was high $(32.51 \mathrm{~h})$. This is due to the fact that oxidative stability is related not only to fatty-acid composition, but also to several other factors, such as pro- and/or antioxidant substances (Ceci and Carelli, 2007). In fact, this sample had the highest phenol contents.

\section{5.: Sterol composition}

Sterols are major constituents of the unsaponifiable fraction. Research has shown that each oily fruit has a characteristic sterol profile which makes it determination an important tool for checking the genuineness of oil. They are important components for the stability of the oil since at high temperature they act as inhibitors of polymerization reactions (Matos et al.,2007).The composition of the sterol fraction of olive oil is a very useful parameter for detecting adulterations or to check authenticity, since it can be considered as a fingerprint (Ben Temime et. al., 2008). Besides, their determination is of major interest due to their health benefits, as mentioned before. In the present work, more than nine sterol compounds were detected and quantified and the results obtained are displayed in Table (4).

One observes that in general they lie within the established regulatory limits except Arbequina virgin olive oil (EC Regulation 1989, 2003) (EEC, 2003). As shown in Table (4), the amounts of individual sterols varied according to the varieties. In the Coratina variety, the highest phytosterol levels were found for $\beta$-sitosterol, followed by 
$\Delta 5$-avenasterol, characteristic of the virgin olive oil in the pulp of the olive (Ben Temime et. al., 2008). The other main sterols were stigmasterol, and campesterol. However, small amounts of cholesterol, clerosterol, sitostanol, $\Delta 5$, 24-stigmastadienol, and $\Delta 7$-avenasterol were also found in all samples except for Arbequina virgin olive oil. These results are in good agreement with data published elsewhere (Rivera del Alamo, et al.,2004, Ceci and Carelli., 2007, Ben Temime et. al., 2008, Mailer et $a l ., 2010)$. Authors have reported that $\beta$-sitosterol, $\Delta 5$-avenasterol and campesterol were the most representative sterols in virgin olive oils from the main Spanish and Portuguese cultivars. $\beta$-sitosterol, the most abundant phytosterol in olive oil, its level represents more than $80 \%$ of total sterols except for Arbequina virgin olive oil. The highest mean percent value of $\beta$-sitosterol was observed in Coratina olive oil (84.24\%), whereas Arbequina olive oil had the lowest one $50.63 \%$ (Table 4 ). $\beta$ Sitosterol content in the Arbequina variety was significantly lower than in the other varieties, for that Arbequina olive oil stood out of IOC limits (IOC, 2006). These values are similar to those reported for other olive oil varieties (Ceci and Carelli, 2007, Mailer et. al., 2010).

The health aspects of $\beta$-sitosterol have recently been reported in several studies. They refer mainly to the reduction of cholesterol levels by opposing its absorption in the intestinal tract and the prevention of many diseases and various types of cancer (colon, prostate, and breast) (Ben Temime et. al., 2008).

Table 4. Sterols fractions of some Egyptian olive oils

\begin{tabular}{|c|c|c|c|c|}
\hline $\begin{array}{l}\text { Sterols fractions (\% of } \\
\text { total sterols) }\end{array}$ & Coratina & Arbequina & Koroneiki & Siwi \\
\hline Cholesterol & 0.30 & 4.45 & 0.45 & 0 \\
\hline 5- $\propto-$ Cholestane & 1.87 & 1.56 & 1.85 & 0.96 \\
\hline Campesterol & 3.15 & 0.67 & 3.90 & 1.36 \\
\hline Stigmasterol & 0.46 & 0.37 & 0.65 & 0.40 \\
\hline Cleroserol & 1.16 & 0.37 & 1.10 & 1.45 \\
\hline$\beta$-sitosterol & 84.24 & 50.63 & 83.63 & 80.33 \\
\hline Sitostanol & 1.82 & 3.79 & 1.6 & 1.25 \\
\hline$\Delta$-5-avenasterol & 6.12 & 4.75 & 6.32 & 8.66 \\
\hline$\Delta-5,24-$ stigmastadienol & 1.03 & N.D & 1.12 & 1.47 \\
\hline$\Delta$-7-avenasterol & 0.62 & N.D & 1.24 & 1.81 \\
\hline Apparent sitosterols & 94.37 & 59.54 & 93.77 & 93.16 \\
\hline Total sterols (mg/kg oil) & 1562.32 & 2550.62 & 1820.42 & 1912.58 \\
\hline $\begin{array}{l}\text { Campesterol / } \\
\text { Stigmasterol }\end{array}$ & 6.85 & 1.81 & 6.00 & 3.40 \\
\hline $\begin{array}{l}\text { Unsaponifiable matter } \\
(\%)\end{array}$ & 1.07 & 1.57 & 1.59 & 1.69 \\
\hline
\end{tabular}


Regarding to $\Delta 5$-avenasterol content, Siwi virgin olive oil showed the highest value $(8.66 \%)$, whereas Arbequina virgin olive oil recorded the lowest one $4.75 \%$ (Table 4). In the literature this compound has been associated with antioxidant activity (Ben Temime et. al., 2008).. Our results seem to agree with this, as Arbequina was one of the least stable varieties.

Stigmasterol is related to various parameters of the quality of virgin olive oil. High levels correlate with high acidity and low organoleptic quality . The analyzed samples contained low levels of this sterol, which is indicative that the oil came from healthy fruit (Ben Temime et. al., 2008).

All the olive oil samples analyzed showed low campesterol content, with a global range from $0.67 \%$ (Arbequina olive oil) to $3.90 \%$ (Koroneiki olive oil). Campesterol content was below the limits established by EU Regulations (4\%) in all of the oils studied (EEC, 2003). The levels of $\Delta 5,24$-stigmastadienol was relatively low in all studied virgin olive oils except for Arbequina olive oil was not detected. $\Delta 5,24$ stigmastadienol percent ranged from $1.03 \%$ (Coratina olive oil) to $1.47 \%$ (Siwi olive oil). As regards other authenticity indices established by the European legislation (EEC, 2003), cholesterol percentages were below the established limits of $0.5 \%$ except for Arbequina virgin olive oil and the percentages of stigmasterol were lower than those of campesterol in studied olive oils varieties (Table 4).

The highest sitostanol content was found in Arbequina olive oil (3.79\%), whereas Siwi virgin olive oil showed the lowest (1.25\%) (Table 4). The highest $\Delta 7$ avenasterol content was observed in Siwi olive oil (1.81\%), while Coratina olive oil showed the lowest (0.62\%) (Table 4). This compound was not detected in Arbequina olive oil.

In the case of apparent $\beta$-sitosterol, expressed as the sum of the contents of $\beta$-sitosterol and four other sterols formed by the degradation of $\beta$-sitosterol (clerosterol, sitostanol, $\Delta 5$-avenasterol and $\Delta 5,24$-stigmastadienol), all samples analyzed contained more than the established limit of $93 \%$ except for Arbequina olive oil was (59.54\%). (IOC, 2006, EEC, 2003).

All of the olive oil samples studied contained more than $1000 \mathrm{mg} / \mathrm{kg}$ of total sterols, the minimum value established by EU Regulations (EEC, 2003), for the category "extra virgin" olive oil. The lowest level in Coratina olive oil (1562.32 mg/ kg) whereas the highest level in Arbequina olive oil $(2550.62 \mathrm{mg} / \mathrm{kg}$ ) (Table. 4). This is undoubtedly a good characteristic of olive oils, due to the great benefits of these compounds for health, as referred before.

The campesterol/stigmasterol ratio has been reported as a quality index of an oil (Ben Temime et. al., 2008).The campesterol/stigmasterol ratio ranged between 
1.81 and 6.85 for the analyzed oils and the average values were particularly high for Coratina and Koroneiki olive oils (Table 4).

In conclusion, All the analyzed VOOs were classified in the "Extra virgin" category according to the regulated physicochemical parameters, but only $75 \%$ of them qualified if the sterols and fatty acid compositions parameters were also taken into account. Arbequina virgin olive oil stood out of IOC and EU limits (IOC, 2006, EEC, 2003) due to its low $\beta$-sitosterol content and high Cholesterol content.

\section{REFERENCES}

1. Ben Temime, S., H. Manai, K. Methenni, B. Baccouri, L. Abaza, D. Daoud, J. Sanchez Casas, E. Osorio Bueno, M. Zarrouk. 2008. Sterolic composition of Chetoui virgin olive oil: Influence of geographical origin. Food Chemistry 110 (2008) 368-374.

2. Ceci, L. N. and A. A. Carelli. 2007. Characterization of Monovarietal Argentinian Olive Oils from New Productive Zones. J. Am. Oil Chem. Soc. 84:1125-1136.

3. Clodoveo, M. L., D. Delcuratolo, T. Gomes and G. Colelli. 2007. Effect of different temperatures and storage atmospheres on Coratina olive oil quality. Food Chemistry 102 , 571-576.

4. Cossignani, L., M. S. Simonetti and P. Damiani. 2005. Biocatalyzed acidolysis of olive oil triacylglycerols with $9 c, 11 t$ and $10 t, 12 c$ isomers of conjugated linoleic acid Eur. Food Res. Technol., 220, 267-271.

5. Dag, A., Z. Kerem, N. Yogev, I. Zipori, S. Lavee and E. Ben-David. 2011. Influence of time of harvest and maturity index on olive oil yield and quality. Scientia Horticulturae 127 , 358-366.

6. EEC 2003. Characteristics of olive and olive pomace oils and their analytical methods. EEC Regulation 1989/2003. Official J. European Communities, 295, 5766.

7. Elsorady, Muhammad. E. I. 2011. Sensory analysis of some Egyptian olive oils in relation to their volatile compounds and chemical composition. J. Adv. Agric. Res. (Fac. Ag. Saba Basha), vol. 16 (1), 13-42.

8. Gamez-Meza, N., T. A. Nriega-Rodiguez, L. A. Medira-Jularz, J. Ortega-Gracia, R. Cazarazez-Casanova and O. Angulo-Guerrero. 1999. Antioxidant activity in soybean oil of extracts from Thompson grape bagasse. JAOCS, 76, 1445-1447.

9. Gutierrez, R. F. 1989. Determinacion de la estabilidad oxidativa de a- ceites de oliva virgenes : Comparacidn entre el mètodo del oxigen. active (AOM) y el mètodo Rancimate. Grasas y Aceites, 40, 1 - 5. 
10. Ibaneza, E., Andres, M. Hurtado Benavides, Francisco J. Senorans and Guillermo Regleroc. 2002. Concentration of Sterols and Tocopherols from Olive Oil with Supercritical Carbon Dioxide. JAOCS, 79, (12): 1255-1260.

11. Inarejos-García, A. M., M. Santacatterina, M. D. Salvador, G. Fregapane and S. Gómez-Alonso. 2010. PDO virgin olive oil quality-Minor components and organoleptic evaluation. Food Research International, 43: 2138-2146

12. IOC 2006. Trade standard applying to olive oils and olive pomace oils in COI / T. 15 / NC no. 3 / Rev. 2.

13. Kiritsakis, A. K. 1998. Olive Oil Handbook. AOCS Press, Champaign, IL.

14. Mailer, R. J., J. Ayton and K. Graham. 2010. The Influence of Growing Region, Cultivar and Harvest Timing on the Diversity of Australian Olive Oil. J. Am. Oil Chem. Soc.,. 87:877-884.

15. Matos,L. C., S. C. Cunha, J. S. Amaral, J. A. Pereira, P. B. Andrade, R. M. Seabra and B. P. P. Oliveira. 2007. Chemometric characterization of three varietal olive oils (Cvs. Cobrancosa, Madural and Verdeal Transmontana) extracted from olives with different maturation indices. Food Chemistry, 102 : 406-414.

16. Pardo, J. E., M. A. Cuesta, A. Alvarruiz, J. D. Granell and M. Alvarez-Ort. 2011. Evaluation of potential and real qualities of virgin olive oil from the designation of origin (DO) "Aceite Montes de Alcaraz" (Albacete, Spain). Food Chemistry, 124 : 1684-1690.

17. Rivera del Alamo RM, G. Fregapane, F. Aranda, S. Gomez-Alonso and M. D. Salvador. 2004. Sterol and alcohol composition of Cornicabra virgin olive oil: the campesterol content exceeds the upper limit of $4 \%$ established by EU regulations. Food Chem., 84:533-537.

18. Samaniego-Sanchez, C., J. J. Quesada-Granados, Lopez-Garcia de la Serrana, H. and M. C. Lopez-Martinez. 2010. $\beta$-Carotene, squalene and waxes determined by chromatographic method in picual extra virgin olive oil obtained by a new cold extraction system. Journal of Food Composition and Analysis 23 : 671-676.

19. Stefanoudaki, E., A. Koutsaftakis and J. L. Harwood. 2011. Influence of malaxation conditions on characteristic qualities of olive oil. Food Chemistry, 127 : 1481-1486.

20. Szterk, A., M. Roszko, E. Sosinska, D. Derewiaka and P.P. Lewicki, 2010. Chemical composition and oxidative stability of selected plant oils. J. Am. Oil Chem. Soc.; 87:637-645. 


\title{
تركيب الاستيرولات لبعض أصناف زيتون الزيت المنزرعة تحت الظروف المصرية
}

\author{
منير محمد عيد ، محمد السيا إسماعيل الصردى
}

قسم بحوث الزيوت والدهون - معرج بحوث تكنولوجيا الأغنية - مركز البحوث الزراعية - الجبزة - مصر.

تعد الاستيرولات من المواد الغير قابلة للتصبن و من المكونات الهامة لصحه الانسان حيث ان لها القدرة على تقليل امتصـاص الكوليستيرول و مشـاكل القلب. لـذا هنالك اهيـة للتعرف على نركيب لفي الاستيرولات فى زيوت الزينون المصرية ، لذا تم دراسة الأستيرولات لاصناف ( كوراتينا و اربيكينا و

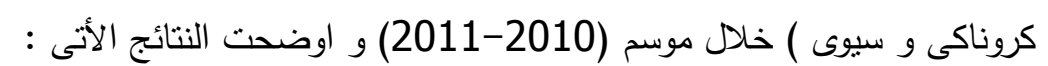

تم التعرف على اكثر من 9 مركبات استيرولية و هى متوقعه و متعارف عليها في زيت الزيتون وتعد في في Cholesterol, هـى المركبـات الاسـتيرولية الرئيسـية بينمـا stigmasterol clerosterol, sitostanol, $\Delta 5,24$-stigmastadienol, and $\Delta 7$-avenasterol فنتواجد بكميات اقل.

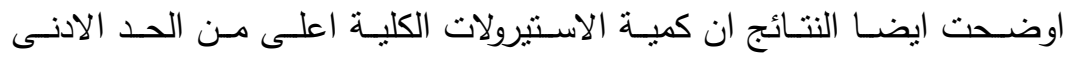

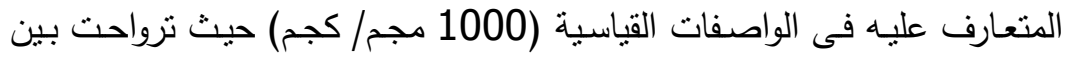

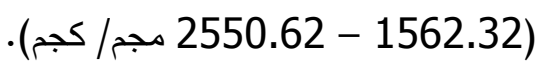

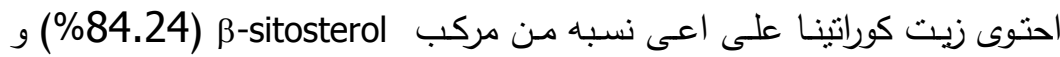

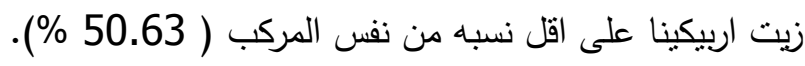

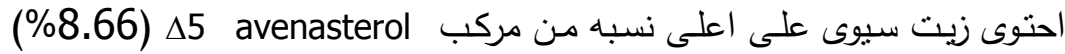

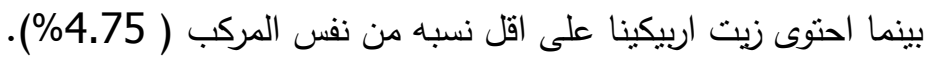

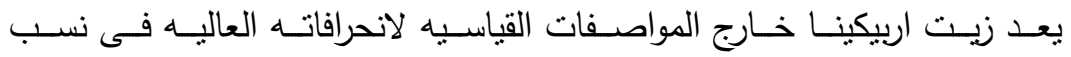
الاستيرولات و الاحماض الدهنيه عن هذه المواصفات القياسية.

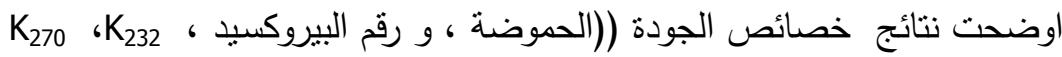

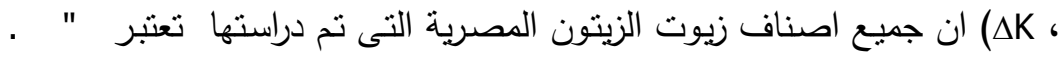

